\title{
TU/e EN⿴HONE

\section{Experimental study of hydrodynamics and thermal behavior of a pseudo-2D spout-fluidized bed with liquid injection}

\section{Citation for published version (APA):}

Sutkar, V. S., Deen, N. G., Patil, A. V., Peters, E. A. J. F., Kuipers, J. A. M., Salikov, V., Antonyuk, S., \& Heinrich, S. (2015). Experimental study of hydrodynamics and thermal behavior of a pseudo-2D spout-fluidized bed with liquid injection. AlChE Journal, 61(4), 1146-1159. https://doi.org/10.1002/aic.14719

\section{Document license: \\ TAVERNE}

DOI:

10.1002/aic.14719

Document status and date:

Published: 01/01/2015

\section{Document Version:}

Publisher's PDF, also known as Version of Record (includes final page, issue and volume numbers)

\section{Please check the document version of this publication:}

- A submitted manuscript is the version of the article upon submission and before peer-review. There can be important differences between the submitted version and the official published version of record. People interested in the research are advised to contact the author for the final version of the publication, or visit the $\mathrm{DOI}$ to the publisher's website.

- The final author version and the galley proof are versions of the publication after peer review.

- The final published version features the final layout of the paper including the volume, issue and page numbers.

Link to publication

\section{General rights}

Copyright and moral rights for the publications made accessible in the public portal are retained by the authors and/or other copyright owners and it is a condition of accessing publications that users recognise and abide by the legal requirements associated with these rights.

- Users may download and print one copy of any publication from the public portal for the purpose of private study or research.

- You may not further distribute the material or use it for any profit-making activity or commercial gain

- You may freely distribute the URL identifying the publication in the public portal.

If the publication is distributed under the terms of Article $25 \mathrm{fa}$ of the Dutch Copyright Act, indicated by the "Taverne" license above, please follow below link for the End User Agreement:

www.tue.nl/taverne

Take down policy

If you believe that this document breaches copyright please contact us at:

openaccess@tue.nl

providing details and we will investigate your claim. 


\title{
Experimental Study of Hydrodynamics and Thermal Behavior of a Pseudo-2D Spout-Fluidized Bed with Liquid Injection
}

\author{
Vinayak S. Sutkar, Niels G. Deen, Amit V. Patil, Elias A.J.F. Peters, and J.A.M. Kuipers \\ Multiphase Reactors Group, Dept. of Chemical Engineering and Chemistry, Eindhoven University of Technology, \\ 5600 MB Eindhoven, The Netherlands \\ Vitalij Salikov, Sergiy Antonyuk, and Stefan Heinrich \\ Institute of Solids Process Engineering and Particle Technology, Hamburg University of Technology, \\ 21073 Hamburg, Germany
}

\author{
DOI 10.1002/aic.14719 \\ Published online January 10, 2015 in Wiley Online Library (wileyonlinelibrary.com)
}

\begin{abstract}
A novel nonintrusive technique is presented to investigate hydrodynamic and thermal behavior of gas-solid spoutfluidized beds with liquid injection, by simultaneously capturing visual and infrared images. Experiments were performed in a pseudo-2D bed with draft plates filled with glass or $\gamma$-alumina particles to investigate the effect of liquid injection and particle properties on the flow characteristics. For the glass particles under dry and wet conditions, timeaveraged particle velocities show similar quasi-steady-state behavior. However, under wet conditions, lower particle velocities were observed in both spout and annulus as compared with the dry system. Whereas, $\gamma$-alumina particles do not show considerable variation in the particle velocities under dry and wet conditions and fluidize well at higher liquid injection rates. Additionally, for the glass particles, the particle temperature significantly decreases as compared to the $\gamma$-alumina particles. (C) 2015 American Institute of Chemical Engineers AIChE J, 61: 1146-1159, 2015
\end{abstract}

Keywords: spout-fluidized bed, particle image velocimetry, infrared thermography, liquid injection

\section{Introduction}

Gas-solid spout-fluidized beds with liquid injection are commonly used in a number of applications involving physical and/or chemical transformations in food, pharmaceutical, and chemical industries. This is because these beds combine salient features of both spouted and fluidized beds, that is, intense gas-solid mixing and excellent heat and mass transfer characteristics. A detailed discussion on other distinguishing features of the spout-fluidized beds can be found in Refs. [1 and 2]. Spout-fluidized beds can be operated with fine and coarse particles possessing wide size distributions. As the development of spout-fluidized beds by Chatterjee, ${ }^{3}$ a series of modifications were suggested to improve the bed performance like: geometrical configurations (rectangular, conical bottom, and slotted rectangular), multiple and elevated spouts, and insertion of a draft tube inside the bed. The insertion of a draft tube in a spout-fluidized bed comprises an additional flexibility to control the particle velocity, bed porosity, and gas residence time by adjusting the operating parameters and the geometrical configurations, for example, the entrainment height and the draft tube dimension. For a more detailed discussion, refer to the work of Refs. 4 and 5 . Further, Nagahashi et al. ${ }^{6}$ studied the effect of water addition in a half cylindrical spouted bed with and without draft

\footnotetext{
Correspondence concerning this article should be addressed to N. G. Deen at N.G.Deen@TUe.nl.

(C) 2015 American Institute of Chemical Engineers
}

tube for polystyrene particles $\left(d_{\mathrm{p}}=6 \mathrm{~mm}\right)$ and compared the results with previous experiments performed on fluidized beds. Their results revealed that injection of liquid in a spouted bed leads to a lower minimum spouting velocity. Spouted beds show high local liquid concentration near the spout, contrary to bubbling fluidized beds where uniform liquid spreading was observed (this results in a lower bed porosity and enhanced aggregate formation, hence higher interstitial gas velocities). Eventually, this leads to completely different bed dynamics.

Representative chemical processes utilizing spout-fluidized beds with draft plates and liquid injection include granulation, coating, and olefins polymerization. In the former, a liquid binder (suspensions, solutions, and melts) mixed with a solvent is atomized on the fluidizing particles to form bigger granules through a layer-wise progressive particle growth. ${ }^{7}$ The liquid injection also leads to improved handling properties and product quality (appearance, dust formation, color, and smell) and provides external protection by isolating active ingredients from exposure to the surrounding. In polymerization, the catalyst particles (anionic, cationic, free-radical, Ziegler-Natta, etc.) are fluidized under reactive operating conditions using a monomer gas (olefins, polar vinyl, acetylene, etc.). The reaction heat can be removed by injecting a liquid solvent, because the latent heat of liquid evaporation is very high and provides very efficient local heat removal. This mode of operation lowers the risk of hot-spot formation.

In these types of processes, the formation of agglomerates is undesirable. However, a small change in the operating or 


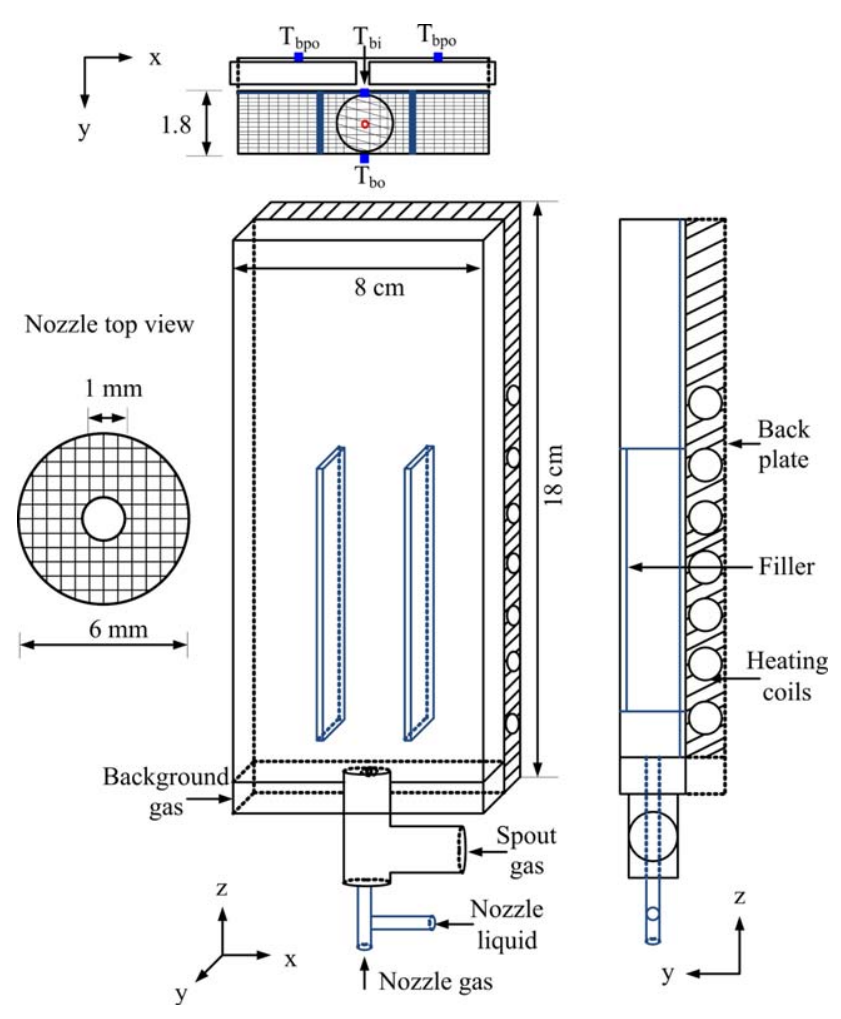

Figure 1. Schematic overview of a spout-fluidized bed with draft plates, illustrating the position of the temperature measurement points (not to scale).

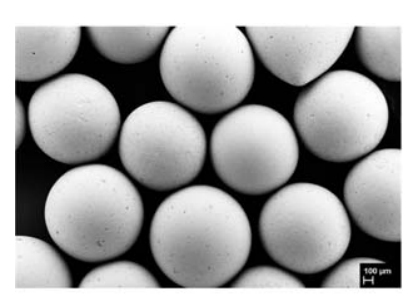

(a) Glass

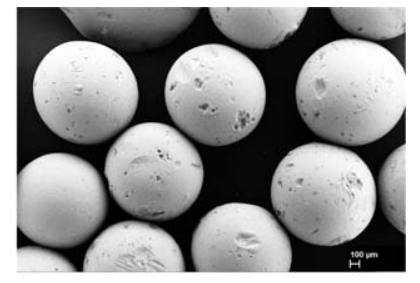

(b) $\gamma$-aluminum oxide

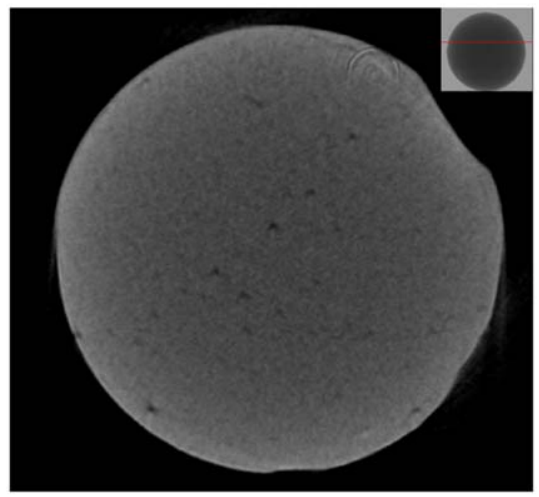

(c) Internal porous structure of $\gamma$ aluminum oxide

Figure 2. SEM snapshots of (a) glass and (b) $\gamma$-aluminum; (c) internal porous structure of $\gamma$-aluminum particle obtained from X-ray tomography.
Table 1. Physical Properties of the Particles Used in the Experiments

\begin{tabular}{lccc}
\hline Property & Glass & $\gamma$-Aluminum Oxide & Unit \\
\hline Internal structure & Nonporous & Porous & - \\
$d_{\mathrm{p}}$ & $1 \pm 0.05$ & $0.9-1.1$ & $\mathrm{~mm}$ \\
$\rho_{\mathrm{p}}$ & 2526 & 1040 & $\mathrm{~kg} / \mathrm{m}^{3}$ \\
$u_{\mathrm{mf}}$ & 0.64 & 0.33 & $\mathrm{~m} / \mathrm{s}$ \\
$e_{\mathrm{n}}$ & 0.97 & 0.74 & - \\
\hline
\end{tabular}

process conditions (fluidization velocity, bed temperature, humidity of the inflow, liquid injection rate and droplet-size distribution, etc.) often leads to excessive and uncontrollable particle agglomeration, and hot- and cold-spot formations due to an uneven liquid distribution. This eventually leads to poor bed performance due to local defluidization and enhanced agglomerations/particle-lump formation (also referred as "wet quenching"). Recently, fluidized bed dynamics with cation exchange resin particles $\left(d_{\mathrm{p}}=683 \mu \mathrm{m}\right.$ and $\left.\rho_{\mathrm{p}}=1290 \mathrm{~kg} / \mathrm{m}^{3}\right)$ were studied by measuring the pressure drop and acoustic signals and capturing high-speed images with liquid addition. ${ }^{8}$ Their study provides guidelines for industrial operation involving liquid injection. Intense evaporation often leads to

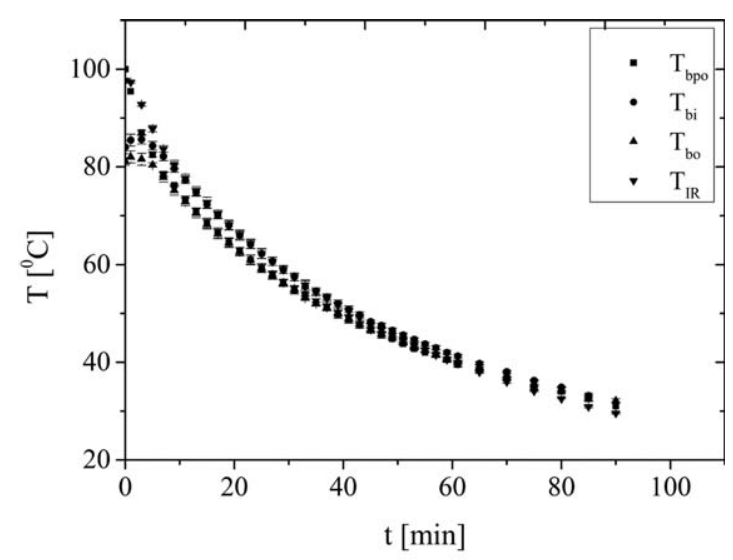

(a)

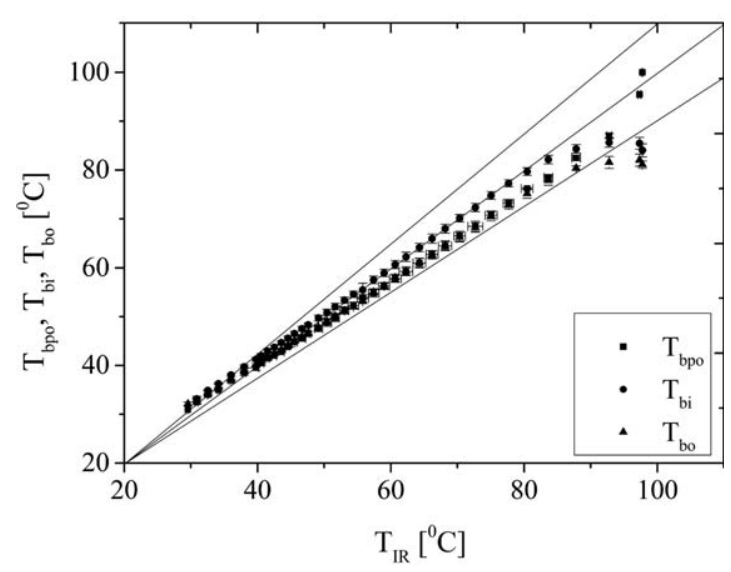

(b)

Figure 3. Variation (a) and comparison (b) of temperature in a fixed bed of glass particles during cooling using thermocouples located at the back plate $\left(T_{\text {bpo }}\right)$, inner bed surface $\left(T_{b i}\right)$, outer sapphire window $\left(T_{\mathrm{bo}}\right)$, and recorded using the IR camera ( $\left.T_{\mathrm{IR}}\right)$. 


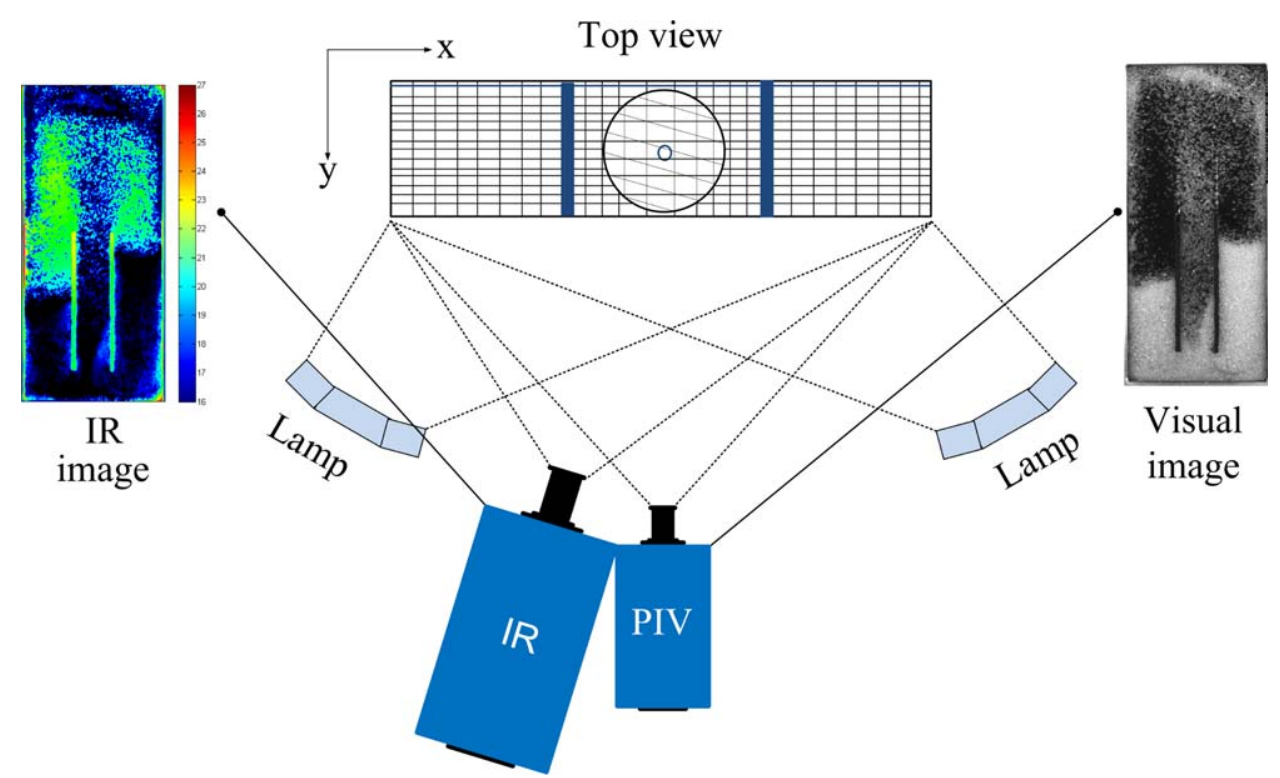

Figure 4. Schematic representation of experimental setup showing location of the visual and IR cameras for a spout-fluidized bed with draft plates.

[Color figure can be viewed in the online issue, which is available at wileyonlinelibrary.com.]

accumulation of a thick vapor layer around the particle, which may inhibit the direct particle-droplet contact, that is, nonwetting contact or Leidenfrost regime. ${ }^{9}$ Under these conditions, the heat flux near the contact area significantly decreases, despite of the high-temperature gradient across the vapor layer. Excessive liquid addition can lead to local defluidization and uncontrolled particle agglomeration due to enhanced interparticle forces, leading to a significant variation in the physical properties and appearance of the particles. ${ }^{10}$ This may lead to bigger agglomerates with a higher weight and size, which makes fluidization difficult. Additionally, the local process conditions and moisture distribution also strongly influence the overall drying rate and agglomeration kinetics.

A detailed understanding of complex multiphase and multiscale interactions together with hydrodynamic and thermal flow behavior are of primary importance for the process design and scale-up. This can be achieved by performing detailed experimental studies addressing both the hydrodynamics and thermal aspects. The experimental studies reported in literature include: pressure drop analysis, ${ }^{11}$ temperature measurements near the injection point or in the whole water atomized gas-solid fluidized bed, ${ }^{12,13}$ fiber optical probe measurements of solids concentration and particle velocity under dry and wet conditions, ${ }^{14}$ and triboelectric probe measurements. ${ }^{15}$ McDougall et al. ${ }^{11}$ measured the dynamic pressure signals generated during liquid injection (water, 1propanol, and 1-butanol) to identify the bed fluidity and the particle agglomerate formation in a fluidized bed with a twofluid nozzle. Temperature measurements generally provide point information, but most methods are not adequate for measuring localized conditions under a transient state. This may be circumvented by measuring thermal behavior with an array of thermocouples, but this makes experimentation quite complex. Ariyapadi et al. ${ }^{12}$ experimentally studied the internal flow structure of the liquid jet into a fluidized bed (with fluid catalytic cracking particles of $d_{\mathrm{p}}=70 \mu \mathrm{m}$ ) using a digital $\mathrm{X}$-ray imaging system (60 frames per second). However, these techniques often possess a low resolution with a complex image post processing. By considering this, Briens et al. ${ }^{15}$ have extended triboelectric effect (i.e., electrostatic charges generated during particles collision and friction with particle and metal surface) measurement technique to study the penetration and expansion of a gas-liquid spray in a fluidized bed through a triboelectric current measurement. Even though this technique provides an nonintrusive illustration of free moisture, quantitative data such as particle velocity and porosity are difficult to obtain.

In this work, a novel nonintrusive measurement technique has been developed to identify the hydrodynamics and thermal behavior of gas-solid fluidized beds with liquid injection by synchronizing a visual camera and an infrared (IR) camera. We will show that this technique can reliably identify the spatial distributions of the wet and dry zones inside the bed and is capable of capturing transient bed behavior. First, experiments were carried out to calibrate the IR camera by comparing the obtained temperature for systems with particles and/or liquid using thermocouples. Subsequently, experiments were performed in a pseudo-2D spout-fluidized bed with draft plates to analyze the effect of the bed temperature, liquid injection rate, and particle morphology using high speed imaging for the fluidized bed spoutingwith-aeration (dispersed spout) regime. The obtained visual images were used to determine the particle velocity through particle image velocimetry (PIV), whereas the liquid distribution in the bed was determined using IR images obtained through infrared thermography (IRT).

\section{Experimental Methods}

In this section, we introduce the experimental setup along with brief description of the pressure measurements, PIV, and IRT.

\section{Experimental setup and calibration of the IR camera}

Experiments were carried in a pseudo-2D spout fluidized bed $\left(W \times D \times H=8 \times 1.8 \times 18 \mathrm{~cm}^{3}\right)$ as shown in Figure 1 


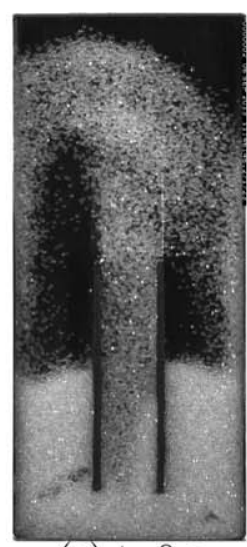

(a) $t=0 \mathrm{~s}$

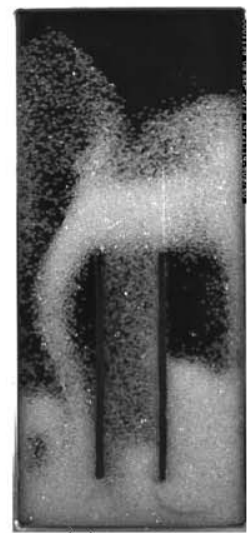

(e) $\mathrm{t}=0 \mathrm{~s}$

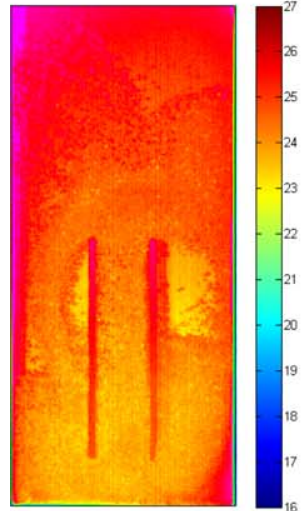

(i) $\mathrm{t}=0 \mathrm{~s}$

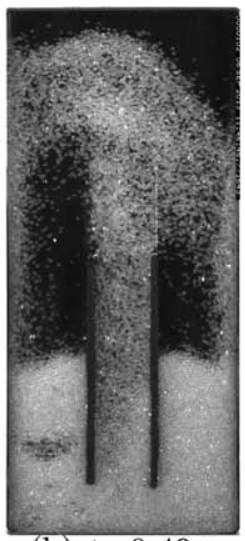

(b) $\mathrm{t}=0.49 \mathrm{~s}$

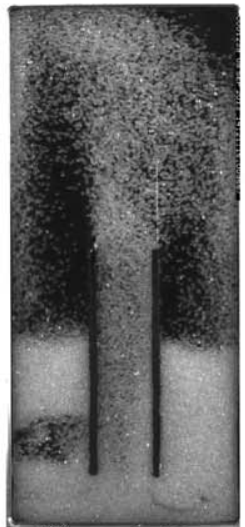

(f) $\mathrm{t}=0.49 \mathrm{~s}$

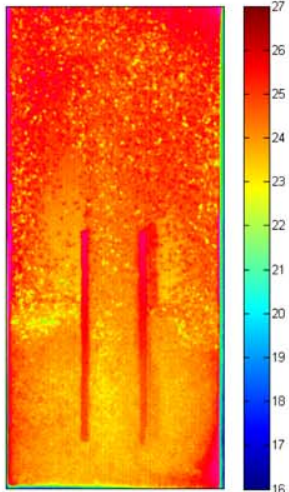

(j) $\mathrm{t}=0.49 \mathrm{~s}$

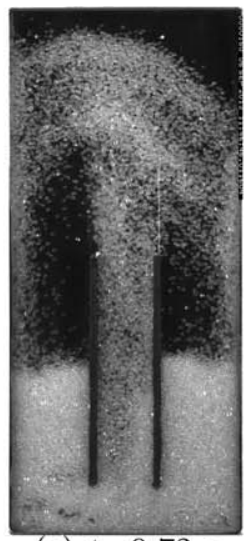

(c) $\mathrm{t}=0.73 \mathrm{~s}$

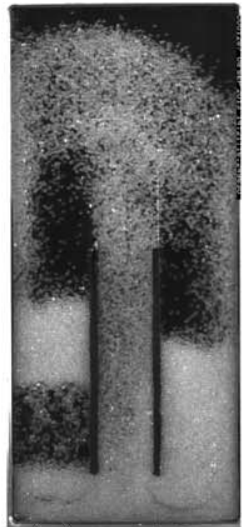

(g) $\mathrm{t}=0.73 \mathrm{~s}$

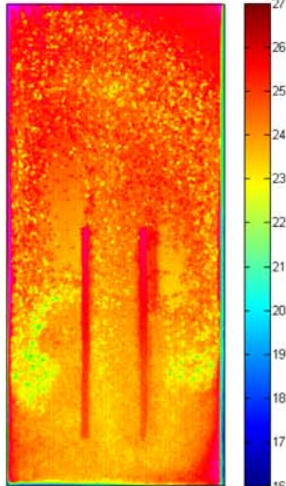

(k) $\mathrm{t}=0.73 \mathrm{~s}$

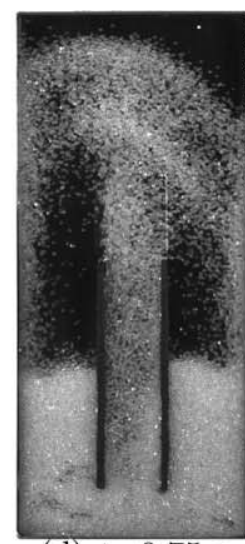

(d) $\mathrm{t}=0.75 \mathrm{~s}$

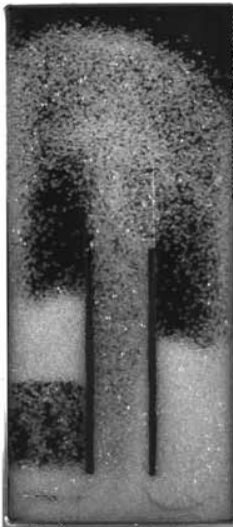

(h) $\mathrm{t}=0.75 \mathrm{~s}$

Figure 5. Visual (a-h) and IR (i-l) snapshots (for $t<1 \mathrm{~s}$ ) of fluidized bed spouting-with-aeration (dispersed spout) regime for dry (a-d) and wet (e-l) systems for glass particles at back plate temperature of $30^{\circ} \mathrm{C}$ and liquid injection rate of $0.089 \mathrm{~mL} / \mathrm{s}$.

The colors in the IR snapshots indicate the temperature in ${ }^{\circ} \mathrm{C}$. [Color figure can be viewed in the online issue, which is available at wileyonlinelibrary.com.]

by injecting nitrogen gas $\left(\rho_{\mathrm{g}}=1.16 \mathrm{~kg} / \mathrm{m}^{3}\right)$ at room temperature. Note that nitrogen gas does not emit the IR radiation due to the nonpolarized state with symmetric atom orientation. Two symmetrical draft plates, each of dimension $W_{\mathrm{dt}} \times D_{\mathrm{dt}} \times H_{\mathrm{dt}}=0.5 \times 1.8 \times 8 \mathrm{~cm}^{3}$, were positioned inside the bed at a distance of $3 \mathrm{~cm}$ from the side walls, $2 \mathrm{~cm}$ from each other, at an entrainment height $h=2 \mathrm{~cm}$ from the bottom. The bed was filled with particles to a static bed aspect ratio $\left(H_{0} / W\right)=0.81$. The front bed wall consists of sapphire glass that allows a high visibility for visual light (with wavelength in the range of 400-700 $\mathrm{nm}$ ) and IR light (with wave- length in the range of 2500-5000 nm). The back wall was made of anodized aluminum with embedded heating coils to maintain the desired temperature up to maximum of $150^{\circ} \mathrm{C}$. A two-fluid nozzle was constructed in accordance with the spout dimension to facilitate simultaneous liquid and spout gas injection and to obtain a large liquid surface area and correspondingly high rate of evaporation. The total liquid flow rate through the nozzle was calibrated by collecting the sprayed liquid amount with and without spout flow for a given time. Experiments were performed by injecting distilled water at a constant rate of $0.089 \mathrm{~mL} / \mathrm{s}$ and room 


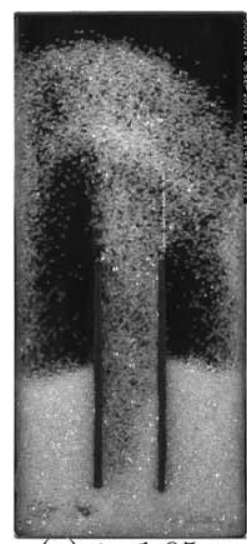

(a) $\mathrm{t}=1.05 \mathrm{~s}$

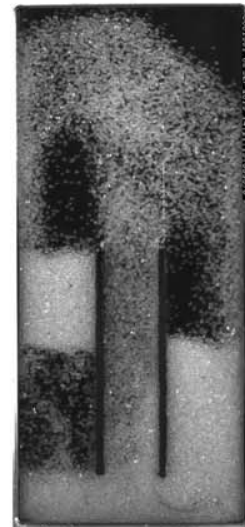

(e) $\mathrm{t}=1.05 \mathrm{~s}$

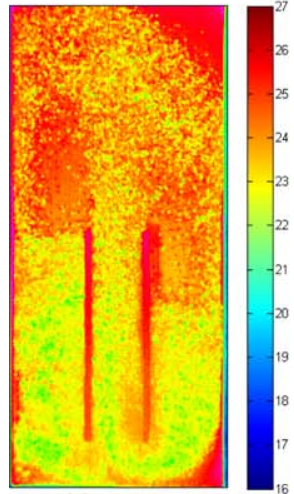

(i) $\mathrm{t}=1.05 \mathrm{~s}$

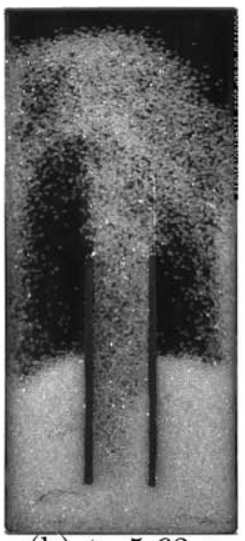

(b) $\mathrm{t}=5.63 \mathrm{~s}$

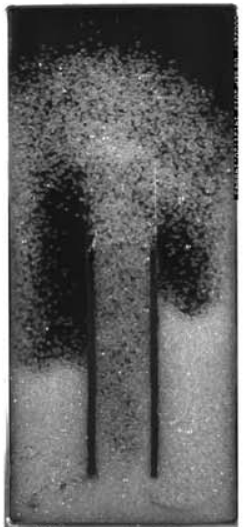

(f) $\mathrm{t}=5.63 \mathrm{~s}$

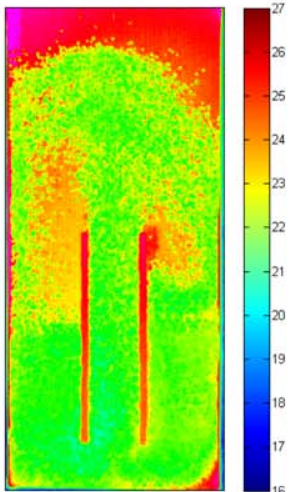

(j) $\mathrm{t}=5.63 \mathrm{~s}$

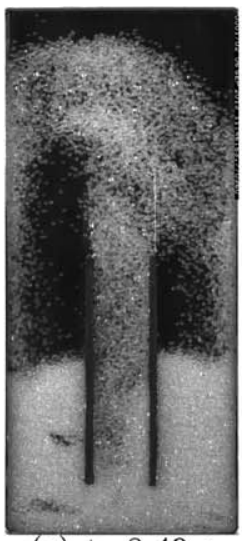

(c) $\mathrm{t}=8.49 \mathrm{~s}$

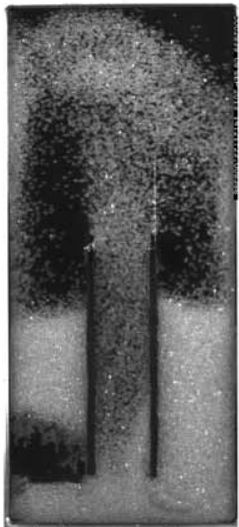

(g) $\mathrm{t}=8.49 \mathrm{~s}$

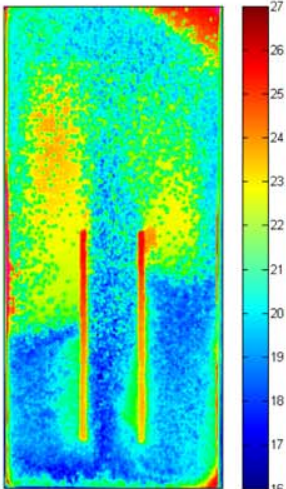

(k) $\mathrm{t}=8.49 \mathrm{~s}$

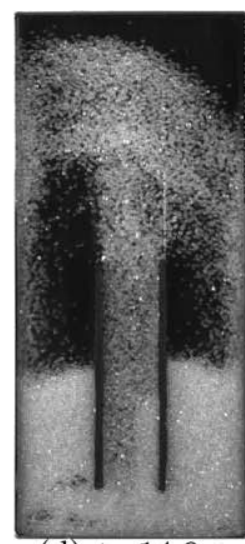

(d) $\mathrm{t}=14.9 \mathrm{~s}$

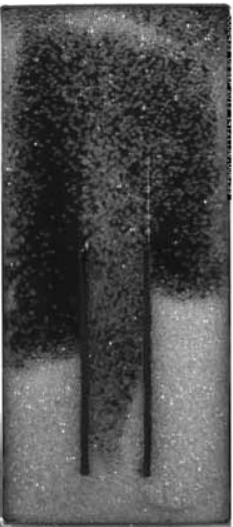

(h) $\mathrm{t}=14.99 \mathrm{~s}$

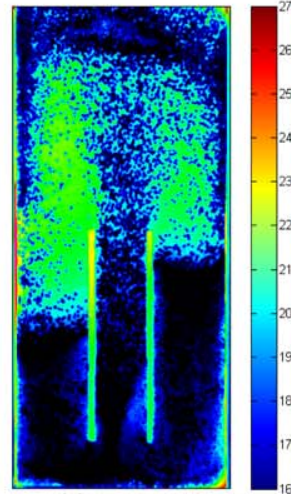

(l) $\mathrm{t}=14.98 \mathrm{~s}$

Figure 6. Visual (a-h) and IR (i-I) snapshots (for $t>1 \mathrm{~s}$ ) of fluidized bed spouting-with-aeration (dispersed spout) regime for dry (a-d) and wet (e-l) systems for glass particles at back plate temperature of $30^{\circ} \mathrm{C}$ and liquid injection rate of $0.089 \mathrm{~mL} / \mathrm{s}$.

The colors in the IR snapshots indicate the temperature in ${ }^{\circ} \mathrm{C}$. [Color figure can be viewed in the online issue, which is available at wileyonlinelibrary.com.]

temperature of $20^{\circ} \mathrm{C}$. Note that a small change in the water temperature can significantly alter the IR camera output signal due to variation in the radiation. Additionally, the droplet size distribution was characterized by capturing 2000 high speed images of the spray. The captured images were analyzed by a MATLAB script to obtain the mean droplet size $\left(d_{\mathrm{d} \text {,mean }}\right)$, which was in the range of $60 \mu \mathrm{m}( \pm 30 \mu \mathrm{m})$ and is well described by a Rosin-Rammler distribution (shape parameter is 1.8 and scale parameter is 0.065$)$. Small droplets $\left(d_{\mathrm{d}}<5 \mu \mathrm{m}\right)$ were not properly captured in the recordings, which however, does not significantly impact the bed dynamics (in reality smaller droplets evaporate quickly). The effect of the liquid injection on the bed dynamics was studied for nonporous glass and porous $\gamma$-aluminum oxide particles. Scanning Electron Microscope (SEM) snapshots of the used particles with internal porous structure of $\gamma$-aluminum oxide are shown in Figure 2. The particle physical properties are listed in Table 1. For each set of experiments, the bed was first fluidized with a batch of clean particles coated with Catanac solution to reduce the influence of electrostatic forces of attractions. The Catanac solution was prepared by mixing $1 \mathrm{~mL}$ of Catanac SP antistatic agent into $100 \mathrm{~mL}$ of ethanol.

The bed was illuminated by two Light Emitting Diode (LED) lamps, placed at an angle of $45^{\circ}$ to minimize 


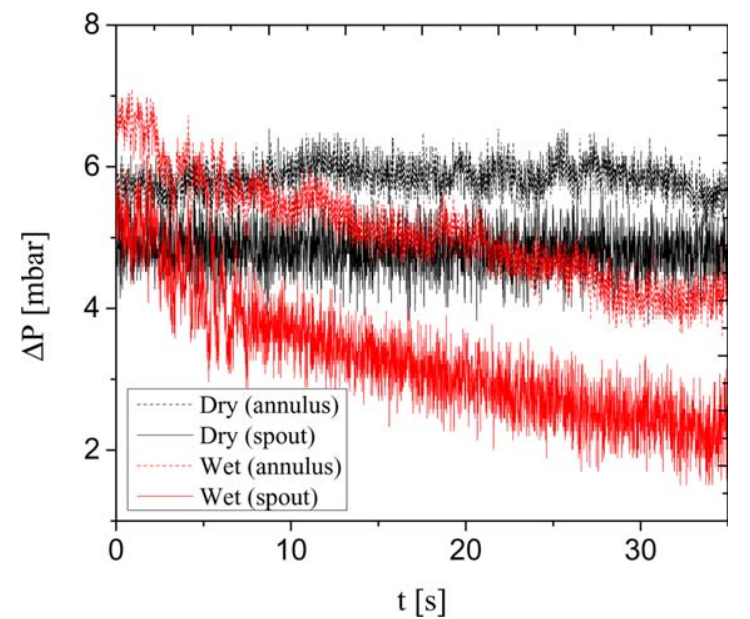

Figure 7. Variation in pressure drop for glass particles under dry and wet conditions at water injection rate of $0.089 \mathrm{~mL} / \mathrm{s}$.

[Color figure can be viewed in the online issue, which is available at wileyonlinelibrary.com.]

reflections. Refraction of IR radiation from surrounding objects was minimized by tilting the IR camera at a small angle. The effect of the surrounding LED light on IR radiation was analyzed by capturing IR images with and without illuminating the bed and obtained results show the same temperature profiles. However, a prolonged illumination by hot lamps leads to an increase in the bed temperature. Therefore, continuous experiments for a longer time were avoided. Pressure fluctuations were measured using two pressure sensors located in the spout and annulus.

Spatial variation in the temperature over a bed surface was measured by the IR camera and compared with a point temperature measurement by thermocouples to calibrate the IRT measurement. The output signal [digital level (DL)] from the IR camera depends on the spectral black-body radiation $M(\lambda$, $T$ ) emitted by the source at a given temperature $T$, the emissivity of the source $\varepsilon(\lambda)$ and sensitivity and response characteristic of the IR detector $D(\lambda)^{16}$ can be expressed as

$$
d(T)=\int_{\lambda_{1}}^{\lambda_{2}} M(\lambda, T) \varepsilon(\lambda) D(\lambda) d \lambda
$$

The lower and upper integration limits $\lambda_{1}$ and $\lambda_{2}$ are based on the sensitive waveband of the detector. For calibration, experiments were performed by filling the bed with either glass particles and/or distilled water. Subsequently, the bed was heated to a maximum temperature of $100^{\circ} \mathrm{C}$. The change in the bed temperature with time (due to natural cooling) was measured using both IRT and four thermocouples, located on the inner and outer bed surface (see Figure 1). Four test cases were selected for calibration namely (i) empty bed (draft plates only), (ii) liquid filled bed (draft plates + water), (iii) fixed bed I (draft plates + particles), and (iv) fixed bed II (draft plates + water + particles). Various test cases were selected to check the dependency of the IR radiation for materials with different emissivity.

For Case (iii), the experiments were carried out by measuring the temperature of the bed filled with glass particles up to $0.18 \mathrm{M}$ height using four thermocouples located on the outer surface of the sapphire window, the inner bed surface, and the outer back plate (as shown in Figure 1).
The measured temperatures are shown in Figure 3 [for Case (iv)]. As time progresses, the temperatures on the inner and outer bed surface decrease exponentially and then remain constant. At high temperatures (above $85^{\circ} \mathrm{C}$ ), the IR camera slightly overpredicts the temperature, whereas it underpredicts the temperature below $40^{\circ} \mathrm{C}$. In addition, the temperature measured by the IR camera has been compared with the temperature measured by thermocouples and shown in Figure 3b, which indicates a good agreement at lower temperature with an accuracy of about $1-1.5^{\circ} \mathrm{C}$. Similar trends were observed for other cases for the bed filled with liquid and/or particles. Also, the calibration procedure was repeated for a fixed bed with injection of gas $\left(u_{\mathrm{g}}<u_{\mathrm{mf}}\right)$ and the obtained results reveal similar temperatures with negligible fluctuations.

\section{Pressure measurements}

Instantaneous pressure measurements were performed using pressure sensors (Sensortechnics; accuracy \pm 0.2 mbar) located in the spout and the annulus. The pressure signals

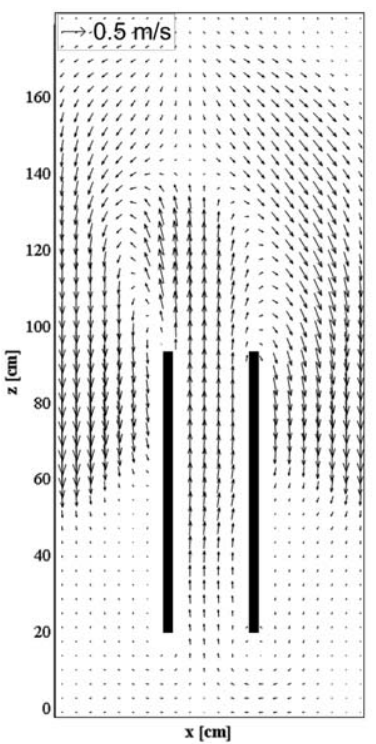

(a) Dry

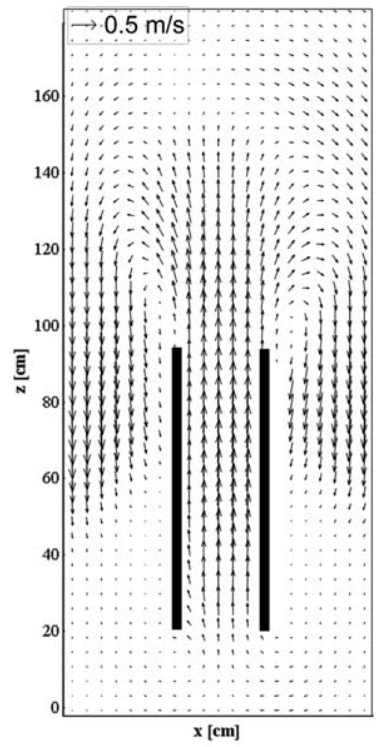

(b) Wet

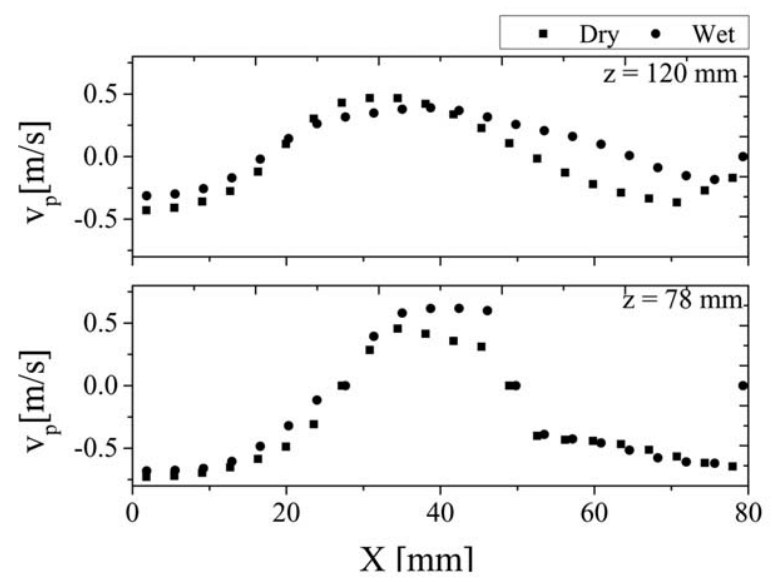

(c) Comparison at $\mathrm{z}=12$ and $7.8 \mathrm{~cm}$

Figure 8. Time-averaged velocity plots for glass particles under dry and wet conditions at back plate temperature of $30^{\circ} \mathrm{C}$ and liquid injection rate of $0.089 \mathrm{~mL} / \mathrm{s}$. 


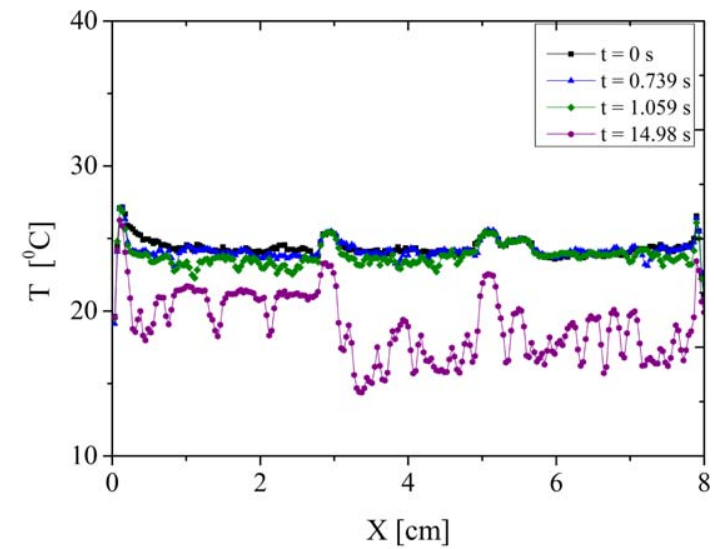

(a)

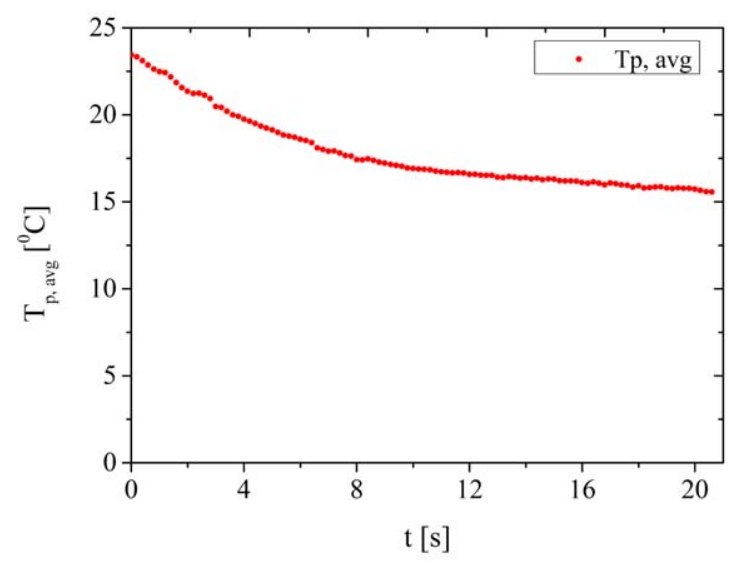

(b)

Figure 9. Variation in (a) the particle temperature along the radial direction at $z=9.2 \mathrm{~cm}$ for various time steps; (b) average particle temperature with time for glass particles at back plate temperature of $30^{\circ} \mathrm{C}$ and liquid injection rate of $0.089 \mathrm{~mL} / \mathrm{s}$.

[Color figure can be viewed in the online issue, which is available at wileyonlinelibrary.com.]

were recorded for $4 \mathrm{~min}$, with $50 \mathrm{~Hz}$ data acquisition rate. For each inflow condition, images were recorded, and pressures were measured.

\section{Particle image velocimetry}

PIV is a nonintrusive measurement technique, which provides instantaneous velocity fields of the particles in dense pseudo-2D beds. In PIV, two subsequent images with a small time interval $(\Delta t)$ were captured and subdivided into interrogation areas depending on the available resolution. A cross correlation is then applied to determine the local spatial average particle displacement $\left(\vec{s}_{\mathrm{p}}\right)$. The particle velocity in each interrogation area is finally determined by

$$
\vec{v}_{\mathrm{p}}(x, t)=\frac{\vec{s}_{\mathrm{p}}}{M \Delta t}
$$

where $M$ is the image magnification factor. During recording, $\Delta t=1 \mathrm{~ms}$ was used and image pairs were recorded at $100 \mathrm{~Hz}$ frequency. The exposure time was adjusted depend- ing on the light intensity and the distance between the camera and the bed. A schematic overview of the experimental setup is shown in Figure 4. Postprocessing was performed in DaVis 8.0 .3 , by setting the interrogation area of $32 \times 32$ pixels with $50 \%$ overlap and by applying a geometric mask at the draft plates location. Outliers were removed using a median filter.

\section{Infrared thermography}

All objects above absolute zero Kelvin emit radiation in both the visual $(0.39-0.7 \mu \mathrm{m})$ and the IR $(0.7-300 \mu \mathrm{m})$ wavelength range, where the intensity of radiation depends on the object temperature. IR cameras facilitated with sophisticated IR detectors and optical technique are capable of measuring the thermal behavior with low response time. Based on this principle, the applicability of coupled IRT and visual measurements to investigate the thermal behavior of fluidized beds under dry conditions was proposed by Tsuji et al. ${ }^{17}$ Recently, Dang et al. ${ }^{18}$ demonstrated the suitability of an IR camera for $\mathrm{CO}_{2}$ gas concentration measurements inside the emulsion phase in a pseudo 2-D-fluidized bed. In this work, we have developed a measurement technique by extending the method of Tsuji et al. ${ }^{17}$ and adapted the experimental and postprocessing techniques proposed by Patil et al. ${ }^{19}$ for the wet system. In wet experiments, both particles and dispersed liquid will absorb part of the radiation at different wavelengths. This allows the IR camera to record the radiation of the back plate, particle, and liquid in terms of DL. After adequate calibration, this technique can be used to provide thermal behavior of the bed.

In this study, the liquid distribution inside the bed was determined by capturing the high speed images using an IR camera (FLIR system, SC7600) operated at $100 \mathrm{~Hz}$, as shown in Figure 4. The accuracy of the IR camera highly depends on the integration time (IT). A high IT generates oversaturated signals whereas a low IT leads to high noise levels. So, for a given system and temperature range (40$100^{\circ} \mathrm{C}$ in our case), the images were captured at a fixed IT, equal to $600 \mu$ s. Twelve thousand IR images were recorded at full resolution $(640 \times 512$ pixels $)$ without disturbing the camera position. Postprocessing was performed in Altair software and MATLAB. Here, it should be noted that the average particle temperature was determined by superimposing visual and IR images by identifying particle location. This analysis procedure provides a flexibility to consider only particle temperature and mask out the back plate temperature. More details about mapping and averaging can be found in Patil et al. ${ }^{19}$

\section{Results and Discussion}

In this section, we present the main results, that is, the effect of liquid injection and bed temperature on wet particulate flows for two particle types namely glass and $\gamma$ aluminum oxide with considerable variations in the physical properties and morphology (density, restitution coefficient, and internal structure) for the fluidized bed spouting-withaeration (dispersed spout) regime $\left(u_{\mathrm{sp}} / u_{\mathrm{mf}}=25.4\right.$ and $\left.u_{\mathrm{bg}} / u_{\mathrm{mf}}=1.25\right)$. We selected this regime for further investigations, because of its steady circulation of particles from spout to the fluidized annulus. In general, the selected flow regime shows a high-particle displacement in between the draft plates, due to high spout velocities with periodic formation and breakup of bubbles near the 


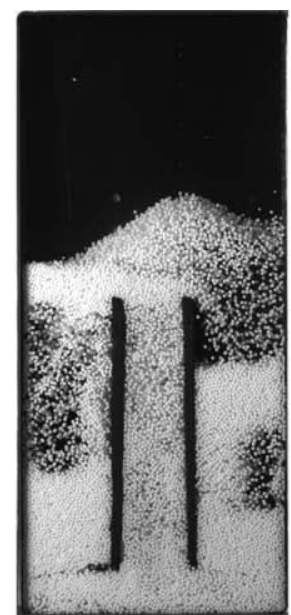

(a) $\mathrm{t}=0 \mathrm{~s}$

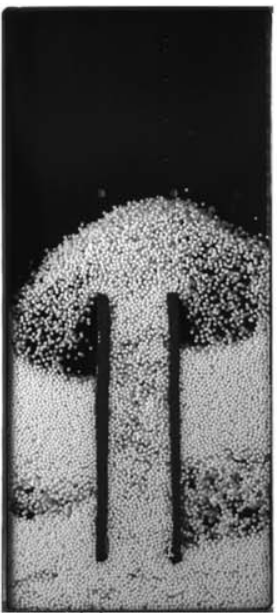

(e) $\mathrm{t}=0 \mathrm{~s}$

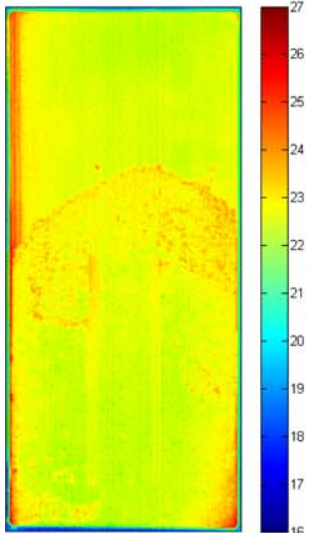

(i) $\mathrm{t}=0 \mathrm{~s}$

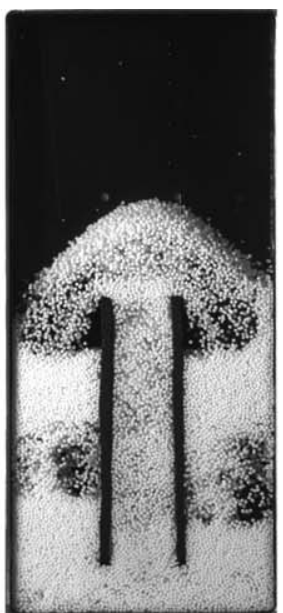

(b) $\mathrm{t}=0.49 \mathrm{~s}$

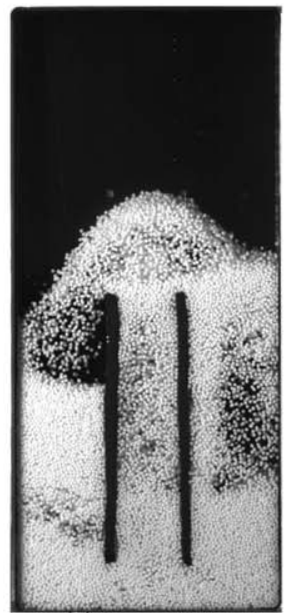

(f) $t=0.49 \mathrm{~s}$

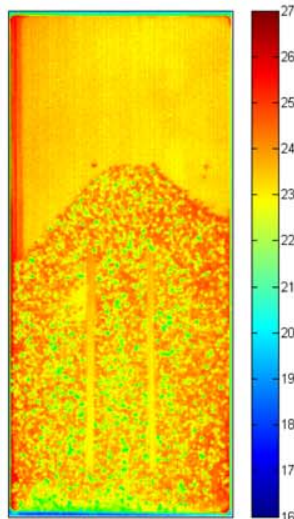

(j) $\mathrm{t}=0.49 \mathrm{~s}$

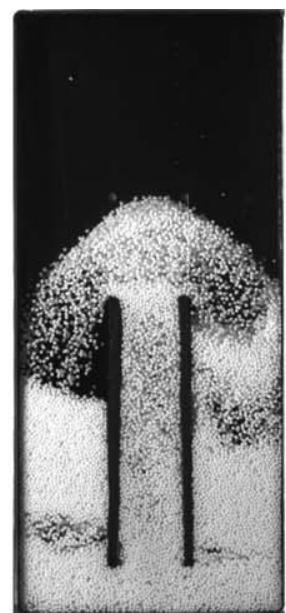

(c) $t=0.73 \mathrm{~s}$

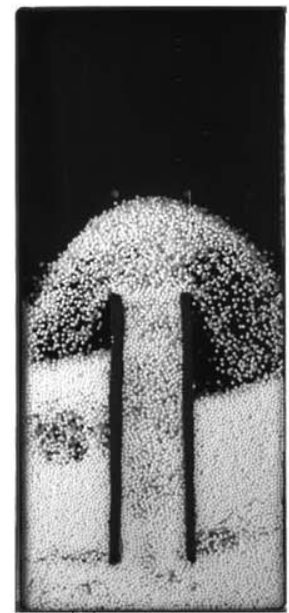

(g) $\mathrm{t}=0.73 \mathrm{~s}$

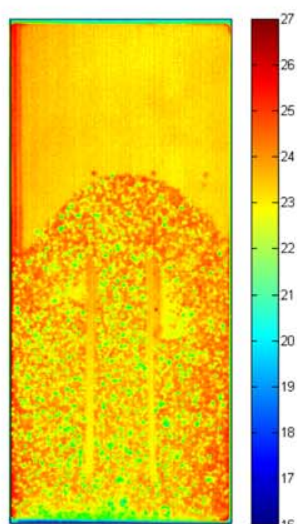

(k) $\mathrm{t}=0.73 \mathrm{~s}$

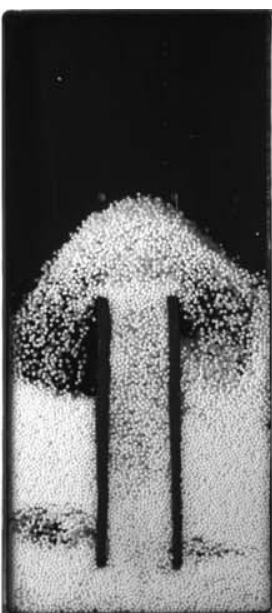

(d) $\mathrm{t}=0.75 \mathrm{~s}$

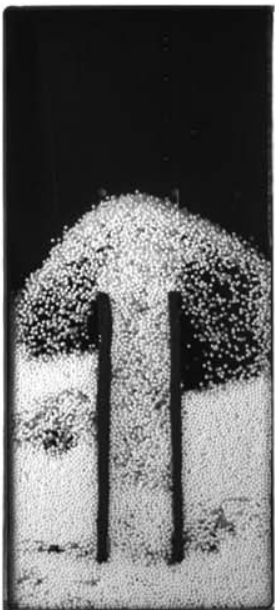

(h) $\mathrm{t}=0.75 \mathrm{~s}$

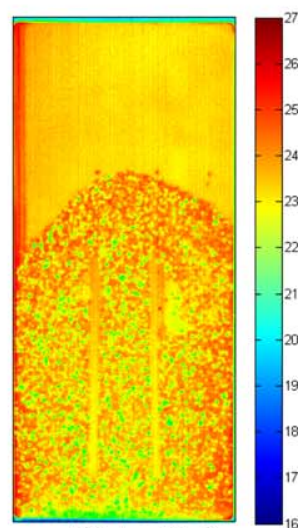

(1) $\mathrm{t}=0.75 \mathrm{~s}$

Figure 10. Visual (a-h) and IR (i-l) snapshots (for $t<1 \mathrm{~s})$ of fluidized bed spouting-with-aeration (dispersed spout) regime for dry $(\mathrm{a}-\mathrm{d})$ and wet $(\mathrm{e}-\mathrm{l})$ systems for $\gamma$-aluminum oxide particles at back plate temperature of $30^{\circ} \mathrm{C}$ and liquid injection rate of $0.089 \mathrm{~mL} / \mathrm{s}$.

The colors in the IR snapshots indicate the temperature in ${ }^{\circ} \mathrm{C}$. [Color figure can be viewed in the online issue, which is available at wileyonlinelibrary.com.]

distributor plate in the annulus. The total system operates like an internally circulating bed. This study will be significant for granulation and coating applications, where variation in the particle properties is observed due to particle-droplet interactions at similar operating conditions with simultaneous heat and mass transfer.

\section{Glass particles}

The dry system shows a quasi-steady behavior with an equal particle distribution between the left and right compartment of the annulus; more discussion about flow patterns can found in Ref. 4. In this case, particles were often elevated to the height in the range of $\approx 17-17.5 \mathrm{~cm}$ with small 


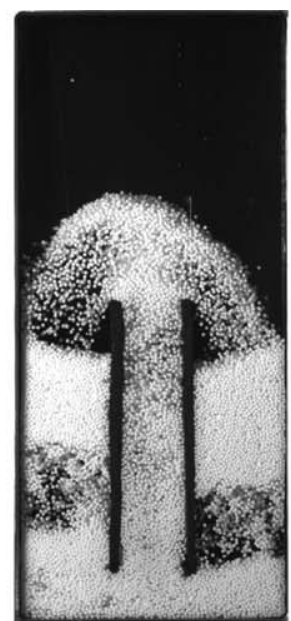

(a) $\mathrm{t}=1.05 \mathrm{~s}$

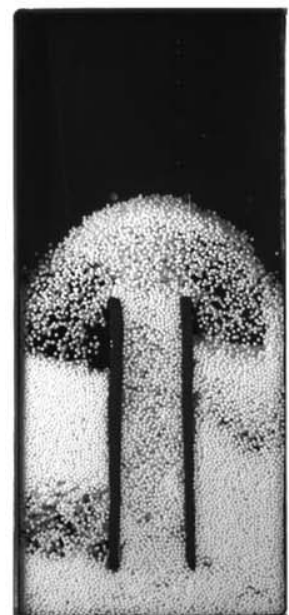

(e) $\mathrm{t}=1.05 \mathrm{~s}$

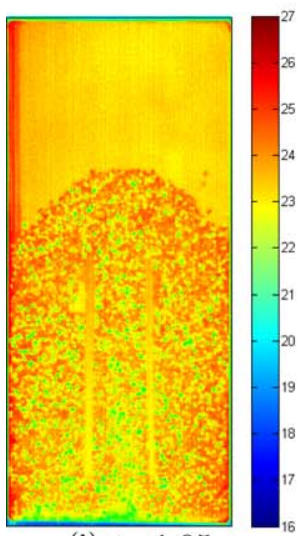

(i) $\mathrm{t}=1.05 \mathrm{~s}$

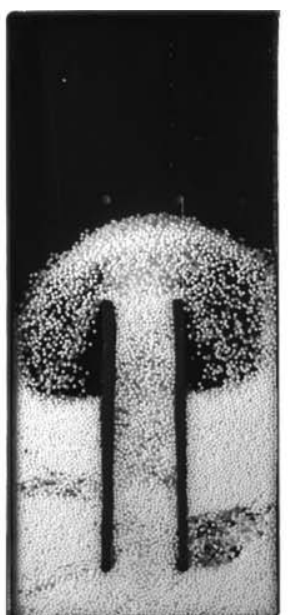

(b) $\mathrm{t}=5.63 \mathrm{~s}$

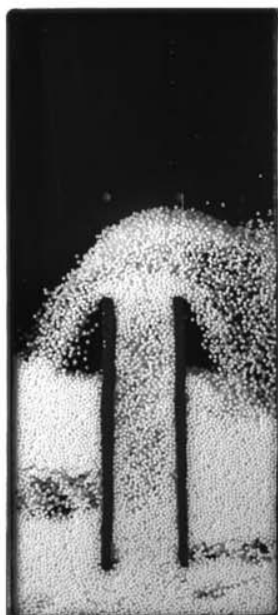

(f) $\mathrm{t}=5.63 \mathrm{~s}$

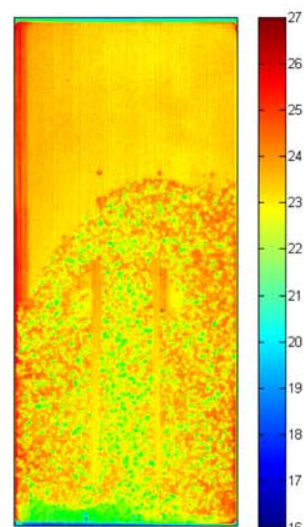

(j) $\mathrm{t}=5.63 \mathrm{~s}$

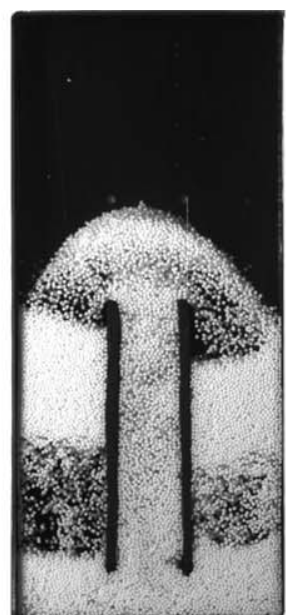

(c) $\mathrm{t}=8.49 \mathrm{~s}$

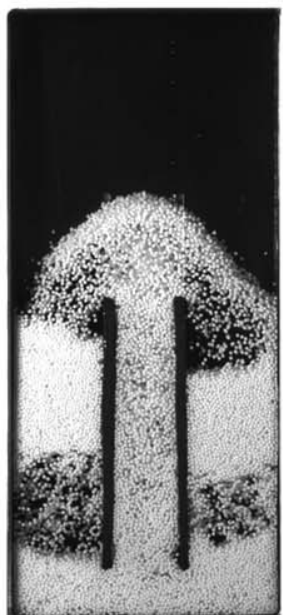

(g) $\mathrm{t}=8.49 \mathrm{~s}$

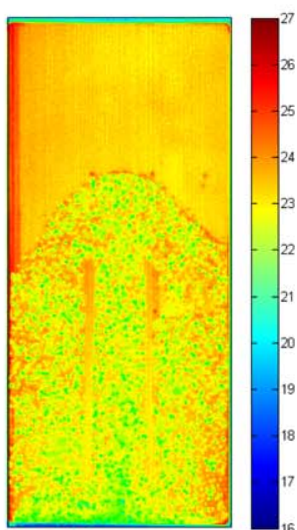

(k) $\mathrm{t}=8.49 \mathrm{~s}$

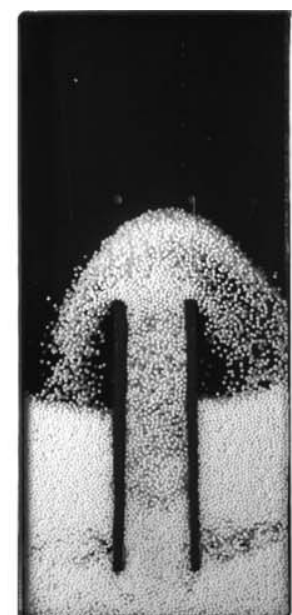

(d) $\mathrm{t}=14.98 \mathrm{~s}$

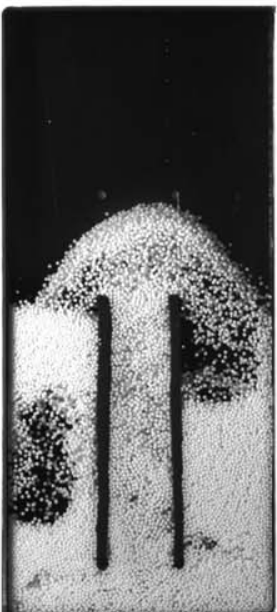

(h) $\mathrm{t}=14.98 \mathrm{~s}$

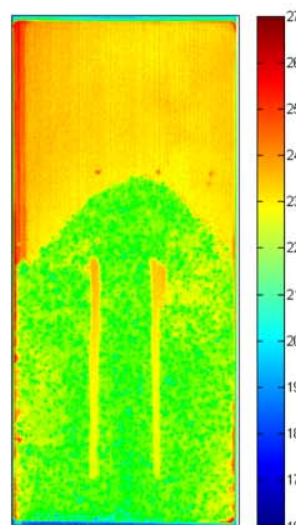

(l) $\mathrm{t}=14.98 \mathrm{~s}$

Figure 11. Visual (a-h) and IR (i-l) snapshots (for $t>1 \mathrm{~s})$ of fluidized bed spouting-with-aeration (dispersed spout) regime for dry $(\mathrm{a}-\mathrm{d})$ and wet $(\mathrm{e}-\mathrm{l})$ systems for $\gamma$-aluminum oxide particles at back plate temperature of $30^{\circ} \mathrm{C}$ and liquid injection rate of $0.089 \mathrm{~mL} / \mathrm{s}$.

The colors in the IR snapshots indicate the temperature in ${ }^{\circ} \mathrm{C}$. [Color figure can be viewed in the online issue, which is available at wileyonlinelibrary.com.]

fluctuations (due to formation and collapse of small bubbles), which can be illustrated from the snapshots shown in Figures $5 \mathrm{a}-\mathrm{d}$ and $6 \mathrm{a}-\mathrm{d}$.

The effect of liquid injection on the bed dynamics was determined by injecting distilled water at $0.089 \mathrm{~mL} / \mathrm{s}$ for $t=21 \mathrm{~s}$ (i.e., total $1.86 \mathrm{~mL}$ of water) though the nozzle located at the bed bottom with a constant back plate temper- ature equal of $30^{\circ} \mathrm{C}$. It should be noted that the liquid injection was started after the particle circulation had become steady. The prevailing flow patterns captured through synchronized visual and IR cameras are illustrated in Figures $5 \mathrm{e}-1$ and $6 \mathrm{e}-\mathrm{l}$. At the beginning of liquid injection, the particle bed height suddenly decreases with an unstable particulate flow behavior in the annulus (see Figure 5e). This may 


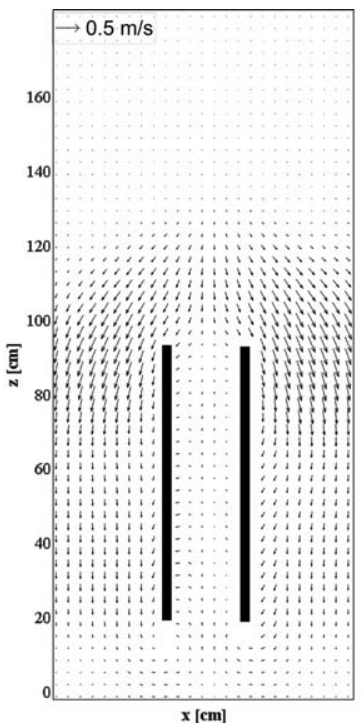

(a) Dry

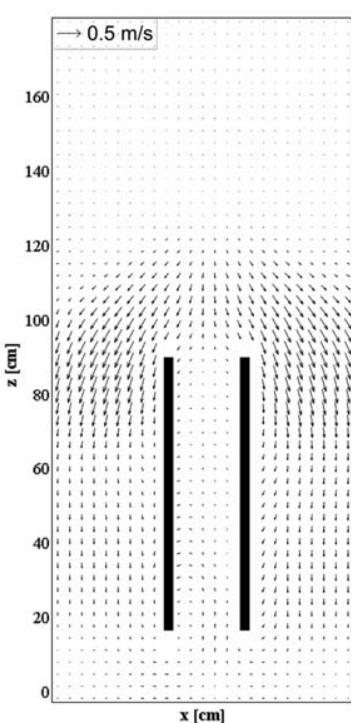

(b) Wet
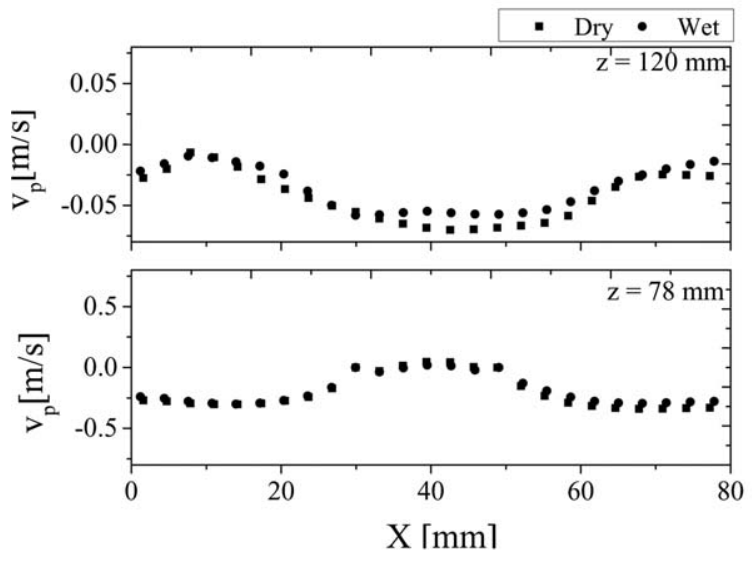

(c) Comparison at $\mathrm{z}=12$ and $7.8 \mathrm{~cm}$

Figure 12. Time-averaged velocity plots for $\gamma$-aluminum oxide particles under dry and wet conditions at back plate temperature of $30^{\circ} \mathrm{C}$ and liquid injection rate of $0.089 \mathrm{~mL} / \mathrm{s}$.

be due to the high resistance experienced by the incoming spout gas due to the accumulation of the wet aggregates/ lumps (with high interaction forces) in the vicinity of the spout near the distributor plate. Subsequently, the wet particles in the spout were transported above the draft plates and fall into the annulus in a structured manner. Figure $5 \mathrm{j}$ shows a random distribution of the wet particles in the zones above the draft plates and top layer of annulus (above the dry particles). As the time progresses, injection of liquid results in a pronounced particle movement in the annulus with periodic slugging, which is mainly attributed to the high gas bypassing from the wet spout region to the dry annulus. Also, at a high spout velocity, the particles are continuously transported from the spout to the annulus loading on a moving slug in the annulus, exerting a high static load. This leads to leaking of particles from the moving slug (which can be seen from Figure 6e). Also, formation of the slug/bubble provides an empty path with less resistance for downward liquid movement, which can be clearly seen from visual and IR images, for example, Figure 6e, i. After $t=1 \mathrm{~s}$, a uniform liquid distribution and particle temperature was observed in the spout and annulus with a lower bed height $\approx 16 \mathrm{~cm}$, (see Figure 6j) without any slugs/bubbles. Continued liquid injection results in saturation of the liquid inside the bed with enhanced particle displacement only in the spout with particle lump formation, which can clearly be observed close to the bed wall in the annulus Figure 6l. This may be due to the reduced minimum fluidization and spouting velocity. ${ }^{6}$ Also, for the nonporous particles, the added liquid occupies a certain space between the particles, which causes an increase in the interstitial gas velocity. Moreover, low particle wettability leads to formation of moderate-size aggregates/lumps and enhances the overall bed dynamics without pronounced defluidization. ${ }^{20}$ McLaughlin and Rhodes $^{21}$ reported that addition of a nonvolatile Newtonian liquid in a gas-solid system often results in the transition in bed behavior from Geldart Group B through Group A and eventually to Group C. The transition boundaries between these three types of behavior are governed by the balance between fluid drag force and the interparticle liquid bridge forces, that is, extent of liquid addition. Whereas, particles in the annulus only show steady circulatory movement from spout to annulus without any slugging.

At the beginning of liquid injection, the bed height suddenly decreases with enhanced particle movement in the annulus. This may be due to the pronounced gas bypassing from the spout to the annulus, occurring due to accumulation of wet particles near the spout region leading to a partial spout blocking. As time progresses, the bed height increases till $t=5 \mathrm{~s}$ and then decreases to a lower value in the range of $\approx 14-14.5 \mathrm{~cm}$ due to higher interparticles interaction forces in the annulus. After $t>5 \mathrm{~s}$, the bed becomes oversaturated with liquid, which completely blocks the inflow gas from the annulus (leading to extensive gas bypassing from annulus to spout), and very few particles are elevated a higher height up to $\approx 17-18 \mathrm{~cm}$.

The variation in the measured pressure signals for both dry and wet system is shown in Figure 7. For a dry system, a stable pressure signal was observed in both spout and the annulus with minor fluctuations in annulus. This is due to the stable circulatory bed behavior with formation/breakup of small bubbles in the annulus. At the beginning of liquid

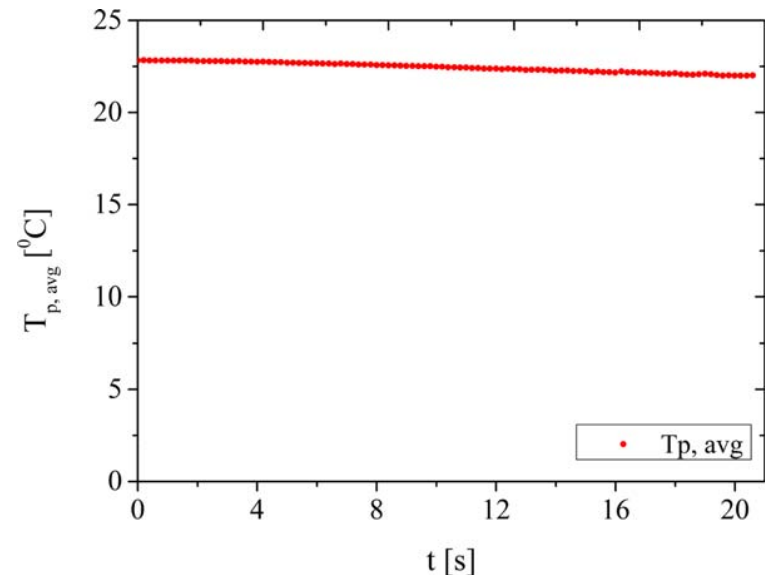

Figure 13. Variation in the particle temperature for $\gamma$-aluminum oxide particles with water injection at $0.089 \mathrm{~mL} / \mathrm{s}$ at back plate temperature of $30^{\circ} \mathrm{C}$.

[Color figure can be viewed in the online issue, which is available at wileyonlinelibrary.com.] 
Table 2. Experimental Settings Used During Analysis of the Effect of Bed Temperature and Liquid Injection

\begin{tabular}{lclc}
\hline Case & Bed Temperature & Particle Type & $\begin{array}{c}\text { Liquid Injection Rate } \\
(\mathrm{mL} / \mathrm{s})\end{array}$ \\
\hline 1 & 30 & Glass & 0.089 \\
2 & 60 & Glass & 0.089 \\
3 & 60 & Glass & 0.18 \\
\hline
\end{tabular}

injection (up to $t=2 \mathrm{~s}$ ), the pressure drop in the spout and annulus was higher than for a dry system with high fluctuations due to the quick reduction in the void space between the particles, and weak wet-dry particle interactions. After $t=2 \mathrm{~s}$ (at a fraction of liquid volume to the bed volume $\left(V_{1} / V_{\text {bed }}\right)$ higher than 0.0023$)$, the pressure drop decreases substantially with intense periodic fluctuations, indicating slugging behavior and gas channeling. From then on, the pressure signal became more stable with reduced fluctuations. Similar trends were observed by $\mathrm{Xu}$ et al. $^{22}$ and Oliveira et al. ${ }^{23}$ This is because the bed gets saturated with liquid leading to agglomerates or lumps. This limits uniform distribution of the incoming gas and encourages channeling and thus affects the pressure fluctuation signals in the bed. Moreover, wet particles often stick to the bed walls. Therefore, total bed mass per unit cross-section supported by the inflow gas is often lower than the dry system, hence lower pressure drop. Figure 8 displays time-averaged particle velocities for glass particles under dry and wet conditions. Higher spout and background velocities lead to a steady particle circulation with stable spouting and fluidization in the annulus for the dry system. While, the wet system possesses similar quasi-steady behavior. For the dry system, intense particle displacements were observed in the spout with a higher bed height as compared with the wet system. Furthermore, for the wet system lower particle velocities were observed in both spout (in upward direction) and annulus (in downward direction) at $z=12 \mathrm{~cm}$ as compared with the dry system. Whereas, at lower height $(z=7.8 \mathrm{~cm})$, the spout exhibits high particle velocities. This is due to the high gas inflow. Variation in the particle temperature along radial direction for various time steps is shown in Figure 9a. As time progress, the particle temperature in the spout decreases more rapidly as compared to the annulus, mainly due to accumulation of the liquid in the spout and liberation of latent heat associated with the phase change. Additionally, average particle temperature profile (Figure 9b) shows decrease in the particle temperature with time till $t=8 \mathrm{~s}$ and then attains a constant value of $15^{\circ} \mathrm{C}$.

\section{$\gamma$-Aluminum oxide particles}

The effect of the particle porosity and wettability on the bed dynamics under dry and wet conditions was investigated by studying the dynamics of $\gamma$-aluminum oxide particles (see Figure 2c for internal structure).

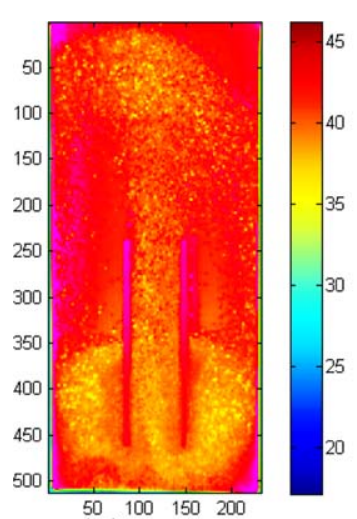

(a) $\mathrm{t}=1.05 \mathrm{~s}$

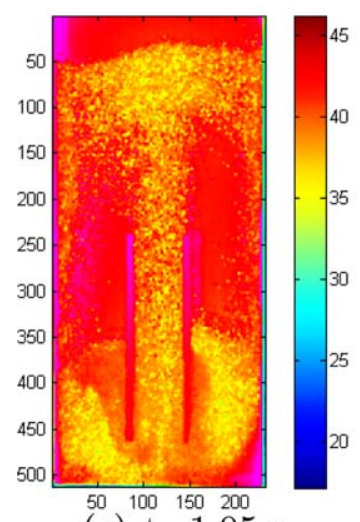

(e) $\mathrm{t}=1.05 \mathrm{~s}$

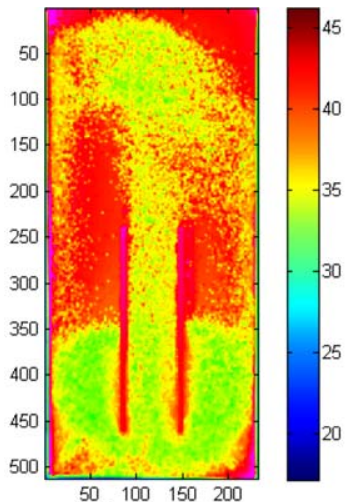

(b) $\mathrm{t}=5.63 \mathrm{~s}$

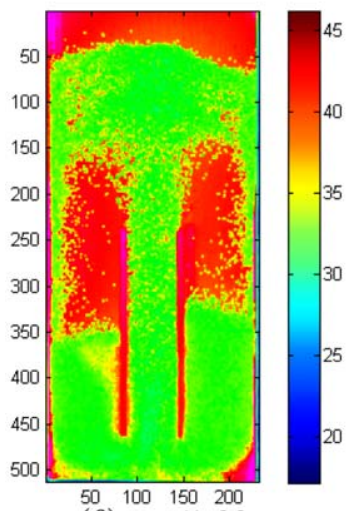

(f) $\mathrm{t}=5.63 \mathrm{~s}$

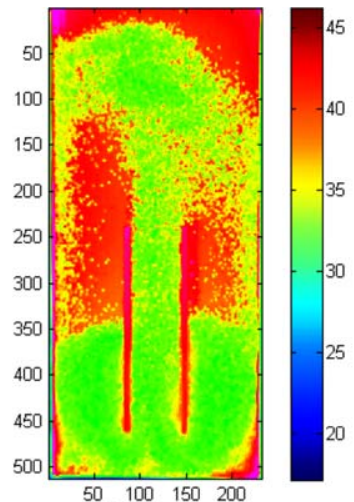

(c) $\mathrm{t}=8.49 \mathrm{~s}$

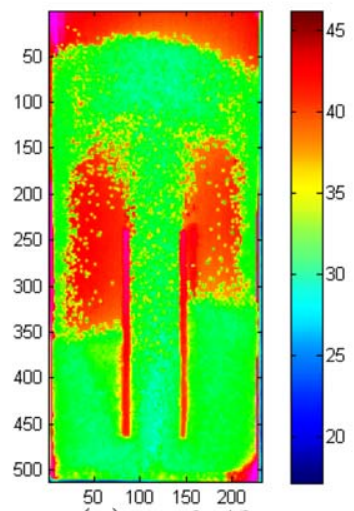

(g) $\mathrm{t}=8.49 \mathrm{~s}$

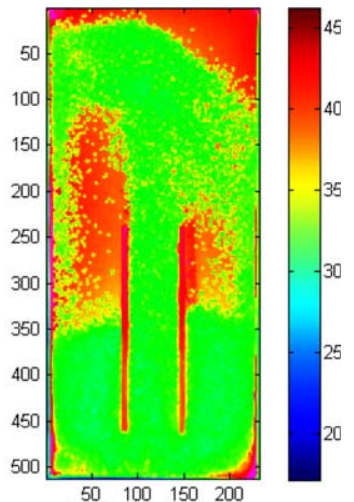

(d) $\mathrm{t}=14.98 \mathrm{~s}$

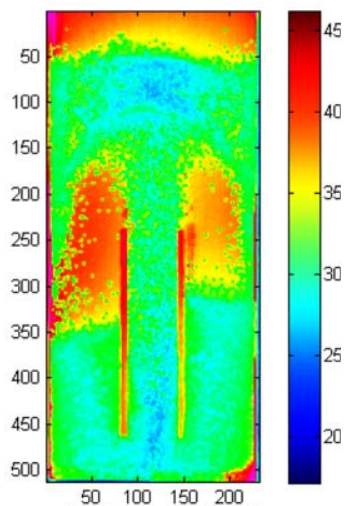

(h) $\mathrm{t}=14.98 \mathrm{~s}$

Figure 14. IR snapshots of the fluidized bed spouting-with-aeration (dispersed spout) regime for glass particles captured at a back plate temperature of $60^{\circ} \mathrm{C}$ with liquid injection rate of $0.089 \mathrm{~mL} / \mathrm{s}(\mathrm{a}-\mathrm{d})$, and $0.18 \mathrm{~mL} / \mathrm{s}(\mathrm{e}-\mathrm{h})$.

The colors in the IR snapshots indicate the temperature in ${ }^{\circ} \mathrm{C}$. [Color figure can be viewed in the online issue, which is available at wileyonlinelibrary.com.] 


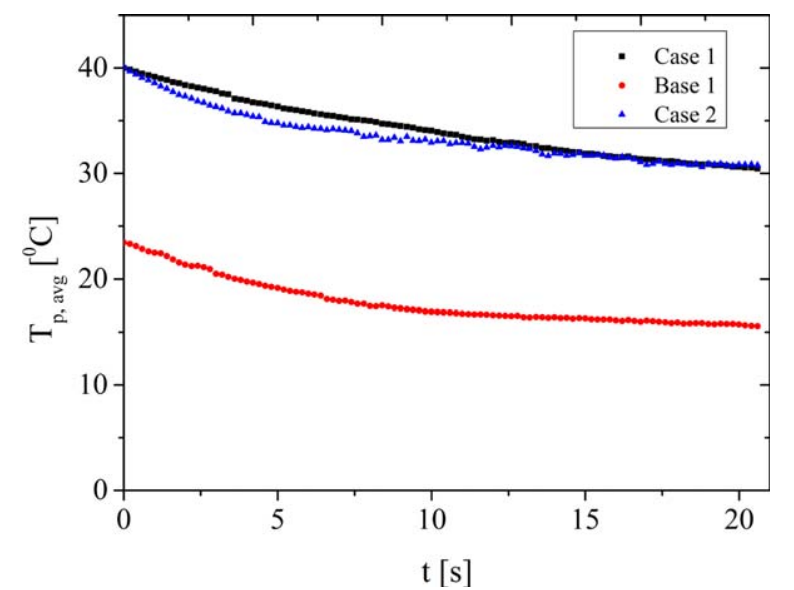

Figure 15. Variation in particle temperature at back plate temperature of $30-60^{\circ} \mathrm{C}$ and liquid injection rate of $0.089 \mathrm{~mL} / \mathrm{s}$ (Case 2) and $0.18 \mathrm{~mL} / \mathrm{s}$ (Case 3).

[Color figure can be viewed in the online issue, which is available at wileyonlinelibrary.com.]

For the dry system, high spout and background velocities results in pronounced particle displacements in both the spout and annulus. Visual and IR snapshots of the flow pattern captured for $\gamma$-aluminum oxide particles are depicted in Figures $10 \mathrm{a}-\mathrm{d}$ and $11 \mathrm{a}-\mathrm{d}$. The particles between the draft plates were transported to a lower height compared to the glass. Moreover, dense particle zones were observed in both spout and annulus. Note that, $\gamma$-aluminum oxide particles shows formation of a cone-like structure above the draft plates which is different as compared to the glass particles. Furthermore, despite similar background velocities, more pronounced particle movements were observed in the annulus with continuous bubbling/slugging, resulting in a better particle mixing and an unstable spout. This may be due to the change in the physical properties of the particles, especially the restitution coefficient and friction coefficient. At a low restitution coefficient, a higher amount of energy is dissipated during interparticle collisions, leading to formation of dense regions, which partially block the space between the draft plates. This results in unstable spouting with pronounced particle cluster formation with higher gas bypassing through the annulus. The characteristic flow patterns after injection of distilled water (at $0.089 \mathrm{~mL} / \mathrm{s}$ ) and captured images are shown in Figures 10 and 11. Here, it should be noted that the liquid injection was started after a steady particle circulation was established. At the beginning of liquid injection, $\gamma$-aluminum oxide particles do not show any sudden change in the flow characteristics like glass particles (see Figure $5 \mathrm{e}$ ). As time progresses, particles in the vicinity of the nozzle absorb the injected liquid and illustrate a uniform distribution of the wet particles (this can be identified by green color) in spout and annulus with reduced slugging. This is mainly attributed to the higher particle weight due to absorption of liquid inside the particles. As liquid injection continues, the particles become more saturated with liquid. Nevertheless, a steady circulation pattern was observed for longer time because the liquid does not accumulate at the particle surface. The $\gamma$-aluminum oxide particles were elevated to a height in the range $\approx 12-13 \mathrm{~cm}$ with lower fluctuations compared to the glass particles. Consequently, the pressure drop for the dry and wet system is rather constant ( $\sim 4 \mathrm{~m}$ bar) both in the spout and annulus.

Time-averaged particle velocity plots for $\gamma$-aluminum oxide particles are shown in Figure 12. The obtained results show similar velocity plots for both dry and wet system, with a slight reduction in the particle velocity in the spout at $z=12 \mathrm{~cm}$. This is mainly attributed to the increase in the particle weight.

Variation in the average particle temperature inside the bed is shown in Figure 13. The particle temperature decreases only slightly with time as compared with the glass particles, because most of the liquid is absorbed inside the particles rather than being evaporated. It finally attains a constant value of $21^{\circ} \mathrm{C}$.

\section{Effect of bed temperature and liquid injection}

In this section, we will discuss the thermal behavior of glass particles at a high back plate temperature $\left(60^{\circ} \mathrm{C}\right)$ and with liquid injection of $0.18 \mathrm{~mL} / \mathrm{s}$ for $21 \mathrm{~s}$. Results are compared with Case 1 as discussed earlier (in Glass Particles section). This study provides guidance on how to fine-tune the operating conditions for continuous operations involving liquid injection without defluidization. More specifically, we highlight the procedure to balance the amount of liquid injected and the bed temperature in such a way that the steady particle circulation is not disturbed. Detailed information about experimental settings is given in Table 2 and IR snapshots showing temperature profiles are depicted in Figure 14. An increase in the back plate temperature at high liquid injection rate (Case 3) does not show any significant variation in the particle temperatures as elucidated in Figure 15. Also, time-averaged particle velocities in both the spout and annulus are slightly higher as compared to Case 1. However, pronounced liquid distribution was observed inside the bed. As time progress (after $20 \mathrm{~s}$ ), particles will stick to the bed surface making the use of PIV less sensible. So, for longer operations, a higher back plate temperature is needed to restore the balance between the rates of heat and mass transfer.

For Case 2, the pressure drop in both the spout and annulus was higher under wet conditions as compared to the dry case. This is mainly because of the enhanced liquid evaporation. At high liquid injection rate (for Case 3), the pressure drop shows similar trends in the spout and annulus as that of Case 1, that is, the pressure drop first increases $(t<8 \mathrm{~s})$ and then decreases gradually, while showing large fluctuations ( $\sim 8 \mathrm{~m}$ bar).

\section{Conclusions}

A novel measuring technique comprising the simultaneous capture of visual and IR images was developed to study the combined hydrodynamic and thermal behavior of gas-solid spout-fluidized beds involving liquid injection. Calibration of the IR camera was carried out by comparing the temperature measured by the IR camera with the temperature of the bed filled with particles and/or liquid obtained using thermocouples. The obtained results show good agreement. Hence, this technique can also be used to quantitatively measure the thermal behavior. In this work, experiments were performed in a pseudo-2D spout-fluidized bed with glass and $\gamma$ aluminum oxide particles under dry and wet conditions for the fluidized bed spouting-with-aeration (dispersed spout) regime. Liquid was injected at a rate in the range of $0.089-$ $0.18 \mathrm{~mL} / \mathrm{s}$ at a constant back plate temperature of either 30 or $60^{\circ} \mathrm{C}$. 
Just after liquid injection, glass particles illustrate a sudden decrease in the particle bed height with an unstable flow pattern in the annulus. This is due to the high resistance experienced by the incoming spout gas due to the accumulation of the wet aggregates/lumps in the vicinity of the spout near the distributor plate. Subsequently, the wet particles in the spout were transported above the draft plates and fall into the annulus in a structured manner, showing random distribution of the wet particles. As time progresses, a pronounced particle movement was observed in the annulus with periodic slugging mainly attributed to the high gas bypassing from the wet spout region to the dry annulus. Continued liquid injection results in saturation of the bed with enhanced particle displacement only in the spout with particle lump formation, due to the reduced minimum fluidization and spouting velocity and increase in the interstitial gas velocity. Glass particles indicate relatively homogenous spreading due to the smooth and nonporous internal particle structure as compared to the $\gamma$-aluminum oxide particles. Glass particles can be handled though, albeit at low injection rates with small droplet diameters. Furthermore, under dry and wet conditions the glass particles show similar quasisteady state behavior. Under wet conditions, lower timeaveraged particle velocities were observed in both spout and annulus at $z=12 \mathrm{~cm}$ as compared with the dry system.

At the beginning of liquid injection, $\gamma$-aluminum oxide particles do not show any unstable flow characteristics like glass particles. As time progresses, particles in the vicinity of the nozzle absorb the injected liquid and illustrate a uniform distribution of the wet particles in spout and annulus with reduced slugging. This is mainly attributed to the higher particle weight due to absorption of liquid inside the particles. Continued liquid injection leads to saturation of the bed. A steady circulation pattern was observed for longer time as the liquid does not accumulate at the particle surface.

$\gamma$-Aluminum oxide particles possess a good operational capacity at high liquid injection rates. This is because the high internal porous structure of the particle facilitates quick liquid absorption and therefore less free moisture on the particle surface. Hence, the interparticle forces are similar to those acting under dry conditions, which allows steady particle circulation. Additionally, $\gamma$-aluminum oxide particles possess a low contact angle as compared with the glass particles, which makes them easier to handle in the presence of liquid injection.

Moreover, glass particles show significant decrease in the particle temperature as compared to the $\gamma$-aluminum oxide.

\section{Acknowledgments}

This research is supported by the Dutch Technology Foundation STW, applied science division of NWO and the Technology Program of the Ministry of Economic Affairs in The Netherlands, as well as by the DFG (German Research Foundation) in Germany. VSS would like to thank J. Zegers (TU/e, The Netherlands) for discussions.

\section{Notation}

\section{Roman symbols}

$$
\begin{aligned}
D & =\text { depth of the plate, } \mathrm{cm} \\
d_{\mathrm{p}} & =\text { particle diameter, } \mathrm{m} \\
d_{\mathrm{d}, \text { mean }} & =\text { drop diameter, } \mu \mathrm{m} \\
e_{\mathrm{n}} & =\text { normal restitution coefficient } \\
H & =\text { height of the plate, } \mathrm{cm} \\
m_{\mathrm{p}} & =\text { particle mass, } \mathrm{kg}
\end{aligned}
$$

$S_{p}=$ average particle displacement, $\mathrm{mm}$

$T=$ time, $\mathrm{ms}$

$T_{\mathrm{g}}, T_{\mathrm{p}}=$ gas and particle temperature, ${ }^{\circ} \mathrm{C}$

$u_{\mathrm{mf}}=$ minimum fluidization velocity, $\mathrm{m} / \mathrm{s}$

$u_{\mathrm{sp}}=$ spout gas velocity, $\mathrm{m} / \mathrm{s}$

$u_{\mathrm{bg}}=$ background gas velocity, $\mathrm{m} / \mathrm{s}$

$v_{\mathrm{p}}=$ particle impact velocity, $\mathrm{m} / \mathrm{s}$

$W=$ width of the plate, $\mathrm{cm}$

\section{Greek symbols}

$\rho_{\mathrm{p}}=$ density of the particle, $\mathrm{kg} / \mathrm{m}^{3}$

\section{Abbreviations and subscripts}

$I R=$ infrared

$I R T=$ infrared thermography

$I T=$ integration time

$P I V=$ particle image velocimetry

\section{Literature Cited}

1. Epstein N, Grace JR. Spouted and Spout Fluid Beds. Cambridge: Cambridge University Press, 2011:29-54.

2. Sutkar VS, Deen NG, Kuipers JAM. Spout fluidized beds: recent advances in experimental and numerical studies. Chem Eng Sci. 2013;86:124-136.

3. Chatterjee S. Spout-fluid bed technique. Ind Eng Chem Process Des Dev. 1970;9:340-341.

4. Sutkar VS, van Hunsel TJK, Deen NG, Salikov V, Heinrich S, Antonyuk S, Kuipers JAM. Experimental investigations of a pseudo2D spout fluidized bed with draft plates. Chem Eng Sci. 2013;102: 524-543.

5. Sutkar VS, Deen NG, Mohan B, Salikov V, Heinrich S, Antonyuk S, Kuipers JAM. Numerical investigations of a pseudo-2D spout fluidized bed with draft plates using a scaled discrete particle model. Chem Eng Sci. 2013;104:790-807.

6. Nagahashi Y, Epstein N, Grace JR, Asako Y, Yokogawa A. Spouting enhancement by addition of small quantities of liquid to gasspouted beds. Can J Chem Eng. 2006;84:527-531.

7. Teunou E, Poncelet D. Batch and continuous fluid bed coatingreview and state of the art. J Food Eng. 2002;53:325-340.

8. Zhou Y, Ren C, Wang J, Yang Y. Characterization on hydrodynamic behaviour in liquid-containing gas-solid fluidized bed reactor. AIChE J. 2013;59:1056-1065.

9. Yang GE, Fan L-S. Droplet-particle collision mechanics with filmboiling evaporation. J Fluid Mech. 2007;573:311-337.

10. Passos ML, Mujumdar AS. Effect of cohesive forces on fluidized and spouted beds of wet particles. Powder Technol. 2000;110:222-238.

11. McDougall S, Saberian M, Briens C, Berruti F, Chan E. Using dynamic pressure signals to assess the effects of injected liquid on fluidized bed properties. Chem Eng Process. 2005;44:701-708.

12. Ariyapadi S, Holdsworth DWC, Norley JD, Berruti F, Briens C. Digital X-ray imaging technique to study the horizontal injection of gasliquid jets into fluidized beds. Int J Chem React Eng. 2003;1:1-16.

13. Heinrich S, Blumschein J, Henneberg M, Ihlow M, Peglow M, Mörl L. Study of dynamic multi-dimensional temperature and concentration distributions in liquid sprayed fluidized beds. Chem Eng Sci. 2003;58:5135-5160.

14. Link JM, Godlieb W, Tripp P, Deen NG, Heinrich S, Kuipers JAM, Schönherr M, Peglow M. Comparison of fibre optical measurements and discrete element simulations for the study of granulation in a spout fluidized bed. Powder Technol. 2009;198:202-217.

15. Briens C, Dawe M, Berruti F. Effect of a draft tube on gas-liquid jet boundaries in a gas-solid fluidized bed. Chem Eng Process. 2009;48: 871-877.

16. Bower SM, Kou J, Saylor JR. A method for the temperature calibration of an infrared camera using water as a radiative source. Rev Sci Instrum. 2009;80:095107-7.

17. Tsuji T, Miyauchi T, Oh S, Tanaka T. Simultaneous measurement of particle motion and temperature in two-dimensional fluidized bed with heat transfer. KONA Powder Part J. 2010;28:167-179.

18. Dang TYN, Kolkman T, Gallucci F, van Sint Annaland M. Development of a novel infrared technique for instantaneous, whole-field, non invasive gas concentration measurements in gas-solid fluidized beds. Chem Eng J. 2013;219:545-557. 
19. Patil AV, Peters EAJF, Sutkar VS, Deen NG, Kuipers JAM. A study of heat transfer in fluidized beds using an integrated DIA/PIV/IR technique. Chem Eng J. 2015;259:90-106.

20. Nagahashi Y, Lee DH, Grace JR, Epstein N, Yokogawa A, Asako Y. Enhancement of large-particle gas-fluidization by adding liquid. AIChE J. 2003;49:675-681.

21. McLaughlin LJ, Rhodes MJ. Prediction of fluidized bed behaviour in the presence of liquid bridges. Powder Technol. 2001;114:213-223.
22. Xu H, Zhong W, Jin B, Wang J. Flow pattern and transition in gasliquid-solid three phase spouted bed. Powder Technol. 2014;267:18-25.

23. Oliveira WP, Souza CRF, Lim CJ, Grace JR. Identification of the state of a wet spouted bed through time-frequency analysis of pressure fluctuation time series. Powder Technol. 2009;87: 289-297.

Manuscript received July 17, 2014, and revision received Oct. 14, 2014. 